\title{
EFFECT OF PEANUT EXTRACT CONSUMPTION ON THE FLUENCY OF BREASTMILK PRODUCTION AMONG LACTATING WOMEN IN KEDIRI
}

\author{
Dewi Kartika Sari \\ Diploma Program in Midwivery, Faculty of Health, Kadiri University
}

\begin{abstract}
Background: Efforts can be made to regulate and increase breastmilk production by providing nutritious food to lactating women. This study aimed to determine the effect of peanut extract consumption on the fluency of breastmilk production among lactating women.

Subjects and Method: This was a quasi experiment using before and after intervention with no control design. This study was conducted at Balowerti Health Center, Kediri, East Java. A subject 16 postpartum feeding mothers selected for this study. The dependent variable was fluency of milk production. The independent variable was provision of peanut extract to lactating women. Changes in percent of breastmilk production fluency before and after provision of peanut extract were analyzed by Chi square.

Results: Percent of lactating women who experienced rough milk production decreased from $50 \%$ before intervention to $43.8 \%$ after intervention, it was statistically significant $(\mathrm{p}=0.002)$.

Conclusion: Consumption of peanut extract by lactating women can effectively increase fluency of breastmilk production.

Keywords: peanuts, breastmilk, fluency, milk production

Correspondence: Dewi Kartika Sari. Diploma Program in Midwivery, Faculty of Health, Kadiri University, Jl. Selomangleng No.1, Kediri, East Java.
\end{abstract}

